\title{
FÉLIX DE AZARA Y GEORGES LUCIEN LECLERC: DOS FORMAS DE ILUMINAR LA NATURALEZA AMERICANA
}

\author{
Andrés Galera \\ Marcelo Frías \\ Dpto. de H. ${ }^{a}$ de la Ciencia - Centro de Estudios Históricos, CSIC - C/ Duque de Medinaceli 6, Madrid

\section{RESUMEN} \\ Estudiar la naturaleza americana fue un reto aceptado por los naturalistas españoles durante la \\ segunda mitad del siglo XVIII, hallando en las expediciones científicas el vehículo adecuado a sus \\ intereses. El presente trabajo analiza la contribucción que Félix de Azara realizó al estudio de la \\ fauna americana durante los años 1781-1801, teniendo como guía la Histoire Naturelle del conde \\ de Buffon.
}

\section{SUMMARY}

Studying the American nature it was a challenge accepted by the spanish naturalists during the second half of the XVIII century, finding the appropriate vehicle to their interests in the scientific expeditions. The present work analyzes the contribution that carried out Félix de Azara to the study of the American fauna during the years 1781-1801, having as a guide the Histoire Naturelle of the count of Buffon.

Durante la segunda mitad del siglo XVIII, América es para la monarquía española sinónimo de ciencia y política; elementos yuxtapuestos por la potestad que dimana de su práctica. En el ámbito del saber, conocer la naturaleza americana es un reto aceptado por los naturalistas españoles, quienes encuentran en la historia natural la llave para salir de la cárcel metafísica donde, a juicio del benedictino Benito Jerónimo Feijoo, estaba secuestrado el entendimiento de nuestros sabios ${ }^{1}$. El arte de navegar al Nuevo Mundo adquiere un componente cognoscitivo que para la ciencia española

1 FEIJOO, B. (1745), «Causas del atraso que se padece en España en orden a las ciencias naturales», en Cartas eruditas y curiosas, t.II, carta XVI. Véase la edición de C. Martín, Alianza Editorial, Madrid, 1970, pp. 166-9. 
significaba su mayoría de edad en la comunidad occidental; sin ocultar un potencial económico: agricultura, botánica, pesca, minería, que define con exclusividad los intereses de la clase dirigente. En esta aventura científico-política Francia y España caminaron juntas en más de una ocasión: a la sombra de Godin y La Condamine viajan Jorge Juan Santacilia y Antonio de Ulloa en 1735, formando parte de la expedición geodésica al virreinato del Perú; en 1777 Hipólito Ruiz, José Pavón y el naturalista francés Dombey, conforman la expedición botánica al Perú y Chile; y en 1781 Félix de Azara principia en Paraguay su lectura del libro de la naturaleza, imbuido, posteriormente, por la luz y las sombras de la Historia Natural de Georges Lucien Leclerc, conde de Buffon. Sin mayor dificultad podríamos ampliar los ejemplos del vínculo franco-español en las ciencias naturales durante la Ilustración. Casimiro Gómez Ortega, José Cavanilles y Pedro Franco Dávila, directores del Real Jardín Botánico, aquéllos, y del Real Gabinete de Historia Natural, éste, son casos relevantes y bien conocidos. Circunstancia propia de una interlocución docente a nivel de maestro y alumno. Francia es, geográfica e intelectualmente, el camino más corto con Europa, espejo de carencias culturales y ejemplo a seguir.

El bagaje naturalista de Félix de Azara es una consecuencia de tan peculiar universidad, un exponente más de aprendizaje por la senda que conduce al parisino Jardín des Plantes. Veamos cómo y porqué.

\section{NAVEGAR A AMÉRICA}

En 1781, expresión del Tratado de San Ildefonso ${ }^{2}$, parte del puerto de Lisboa rumbo a Rio de Janeiro la Comisión de Límites que ha de resolver el conflicto hegemónico entre España y Portugal allende los mares, estableciendo una nueva frontera hispano-lusitana. El ingeniero militar Félix de Azara formó parte de la comitiva, correspondiéndole el reconocimiento del territorio comprendido al norte de Buenos Aires hasta el Paraguay, región donde permaneció hasta el año $1801^{3}$. Una explora-

2 En 1777 España y Portugal firman el tratado de San Ildefonso que dejaba en suspenso las diferencias hegemónicas de ambas monarquías en América. El acuerdo reune aspectos comerciales y geográficos, estableciéndose una nueva delimitación de la frontera hispano-lusitana en América. Portugal renuncia a sus pretensiones sobre el territorio del Sacramento, y recibe a cambio amplias concesiones en los límites de la frontera del Brasil, cediendo a la corona española las islas de Fernando Poo y Annobón, en la costa africana.

3 Nace Félix de Azara el 18 de mayo de 1742 en Barbuñales, Huesca. En 1765 ingresó en la Academia militar de Barcelona, donde alcanza el grado de subteniente de infantería e ingeniero delineador. En 1769 inicia su actividad como ingeniero militar que le conducirá por las plazas de Mallorca, Barcelona y Gerona. En 1774 participa en la campaña militar de Argel, alcanzando el grado de teniente. Habiendo sido designado miembro de la Comisión de Límites, en 1780 recibe el nombramiento de teniente 
ción que le puso en contacto con una naturaleza desconocida, sobre la que atesoró conocimientos anhelados por la ciencia europea. Consecuentemente, su obra Viajes por la América meridional se convierte en fuente obligada de consulta durante la centuria decimonónica, causa de las sucesivas ediciones en francés, alemán, italiano, inglés y castellano, publicadas en la primera mitad del siglo ${ }^{4}$.

A su llegada al Nuevo Mundo, el interés de Azara por el estudio de la naturaleza es un mero deseo de cognición; sus primeras observaciones se realizan sin otro instrumento, mayor conocimiento, ni rumbo, que el afán intelectual. Sin embargo, navegar por el océano de las ciencias naturales deja de ser un simple pasatiempo para convertirse en un proyecto científico dirigido al estudio de la fauna del Paraguay y río de la Plata, con el único auxilio de la obra buffoniana.

En su etapa diletante, la observación de la naturaleza induce en Azara una filosofía sustentada en la diversidad faunística de un ecosistema inerme aún a la acción del hombre. Un mundo armónico donde la vida se expresa en su forma original, sin la ficción de la sociedad civilizada; un lugar donde «los vivientes están en el paraje que les conviene, cuando comen, anidan y giran según el orden primitivo de su naturale$\mathrm{za}, \mathrm{y}$ cuando las especies sin defensa subsisten sin excavar cuevas, sin malicia y sin la menor alteración en su instinto» ${ }^{5}$, se argumenta. El problema radica en la actitud agresiva de la cultura occidental frente a una naturaleza indefensa; un comportamiento capaz de destruir el medio enarbolando la bandera del progreso: «Los naturalistas que vengan después, todo lo hallarán lleno de arrugas y berrugas, desfigurado y pervertido por la mano del hombre, y por los influjos del alimento facticio o de cultivo. Las formas y colores habrán variado igualmente, y gran parte de las castas habrán desaparecido» ${ }^{6}$, concluye.

Bajo esta proclama ecológica Azara descubre la utilidad de la taxonomía. De la multiplicidad de organismos observados en este paraíso terrenal, infiere una necesi-

coronel de ingenieros agregado al cuerpo de Marina. Su estancia americana tuvo una duración de veinte años, regresando a España en 1801, y trasladándose inmediatamente a París. En su estancia visita el Jardín de Plantas y conoce a Cuvier. Regresa a España en 1804 para formar parte de la Junta de Fortificaciones y Defensa de ambas Indias. Fallece el 17 de octubre de 1821. Para la biografía de Félix de Azara véase Álvarez, E. (1935), Félix de Azara, Aguilar, Madrid. GonZÁleZ, J.L., «Apuntes biográficos de don Félix de Azara», en AzARA, F. (1943), Memoria sobre el estado rural del río de la Plata y otros informes, Ed. Bajel, Buenos Aires, pp. VII-CXIV. PIÑERA, A. (1992), El brigadier de la Real Armada e ingeniero militar don Félix de Azara y Perera, Asamblea Amistosa Literaria, Servicio Publicaciones de la Armada, Madrid.

4 La obra se publicó originalmente en francés, París, 1809, 4 vols. La traducción alemana corresponde al año 1810, Berlín; la italiana a 1817, Milán; la inglesa a 1835; y la castellana a 1845, Montevideo. Otras ediciones aparecidas durante el siglo XIX son: Leipzig, 1810; Viena, 1811; y Turin, 1830.

5 AzARa, F. (1789), Apuntaciones para la historia natural de las aves de la provincia del Paragucy. Manuscrito de la biblioteca del Museo Nacional de Ciencias Naturales, t.I, p.7.

6 bidem, p.8. 
dad sistemática, reclama la presencia de un orden que dé sentido al caos informativo de sus numerosas descripciones ${ }^{7}$. Reconoce en la clasificación un elemento artificial, necesario para el desarrollo científico; un instrumento imprescindible cuando la pregunta es ¿qué especies conocemos y cuáles no? Su método incurre en el tradicional raciocinio comparativo que sustenta un organigrama natural definido por analogías y diferencias. Una relación de proximidad morfológica y etológica reune los individuos en especies, cuyas semejanzas determinan los géneros. En la práctica el método no resulta tan eficaz como prescribe la teoría: «Consideraba que si para generalizar adoptaba analogías del tamaño y forma juntaría aves de diversas constumbres: además de que siempre hallaba aves intermedias que no sabía a qué género agregarlas», afirma ${ }^{8}$. La interrogación recae sobre el criterio sistemático, cuestión aún sin resolver para la zoología. Su duda no descansa en la tergiversación de la realidad producida por el artificio taxonómico, es atribuible a las limitaciones intelectuales del hombre para tal cometido; ni conduce a la refutación de la taxonomía en favor del individuo, que aislado no tendría significado en la naturaleza. Involuntariamente, Linneo triunfa sobre Buffon en la búsqueda del saber.

Con este substrato ideológico Félix de Azara recibe en la década de 1790 la Historia Natural de Buffon ${ }^{9}$. Desde este momento su exploración zoológica sigue la huella del maestro, componiendo un monólogo cuyo fin es corrector, donde no ha lugar la descalificación en una crítica que sólo persigue la verdad para, ignorante del óbito del filósofo francés, suministrarle la información necesaria y reparar sus errores: «no debo ocultar que mi intención por muchos años fue enviar todos mis apuntamientos sin publicarlos al mismo Buffon, para que los ordenase y los corrigiese, y para que se corrigiese a su gusto; y lo habría hecho a no haber sabido que había muerto» ${ }^{10}$. Declaración de buenas intenciones que no oculta una valoración negativa de la labor descriptiva realizado por Buffon sobre la fauna del Nuevo Mundo. El yerro se manifiesta en la metodología y en el contenido, las falsas noticias se mezclan

7 Cf. Azara, F. (1802-5), Apuntamientos para la historia natural de los pájaros del Paraguay y del río de la Plata, Vda. de Ibarra, Madrid, t.I, p.V.

8 AzARA, F. (1789), t.I, p.2.

9 La obra de Buffon llegó a las manos de Azara en la década de los noventa, en Buenos Aires. El capitán de fragata Martín Boneo le entregó los doce primeros volúmenes correspondientes a la traducción castellana realizada por José Clavijo y Fajardo, y el resto, por no haber más volúmenes traducidos, corresponden al original francés, y fueron entregados por Pedro Cerviño. Cf. AZARA, F. (1801) Essais sur l'histoire naturelle des quadrupedes de la province du Paraguay, París, t.I, pp. XLIII. En su obra Apuntamientos para la historia natural de los pájaros del Paraguay y río de la Plata, Madrid, 1802, p.VI, Azara explica que Cerviño le entregó la Historia Natural de los Pájaros, escrita en 18 vols. y publicada en París en 1770. Según Sonnini de Manoncour, reponsable de la versión francesa de esta obra, incluida en AZARA, F. (1809), Voyages dans l'Amerique Méridionale, París, t.III y IV, las referencias de Azara a la Histoire naturelle de Buffon corresponden a la edición in-12 de la imprenta real.

11) AzARA, F. (1802-5), t.I, p.VII-VIII. 
con el escaso rigor de las magnitudes y proporciones utilizadas al describir las especies $^{11}$. El fraude descubre la categoría de naturalista de gabinete representada por Buffon, y las fuentes poco fidedignas donde recopiló la información contenida en su obra; circunstancia reivindicada por Azara para excusar la falta: «Como no he leido otra obra que la de Mr. Buffon, me he visto como forzado a preferirle en mis críticas; pero es bien fácil conocer, que no son tanto contra él, como contra los viajeros y naturalistas, de quienes copió los errores que impugno» ${ }^{12}$.

La controversia demanda una mínima acotación. El siglo XVIII fue escenario de un debate zoológico cuyo signo de identidad es el inventario faunístico. Tal circunstancia acentúa el problema de la caracterización de las especies. La dificultad en la identificación estriba tanto en la impericia del naturalista al describir, como en la carencia de un lenguaje común, de un código científico que establezca las reglas del juego - los modos y maneras de conocer la fauna-, dotado del rigor necesario para trasmitir los nuevos saberes. El resultado es un clima dubitativo, propicio a los errores de identidad y a la fantasía.

\section{CLASIFICACIÓN NATURAL}

Establecida queda la necesidad sistemática que el conocimiento de la fauna demanda en Azara, como método necesario para ordenar la información y progresar en la cuantificación de las especies que pueblan la Tierra. De esta actitud metodológica resultan algunas consecuencias de mayor rango en relación con el ideario buffoniano. Nos referimos al método natural y al concepto de especie.

Azara, en su calidad de aficionado, está abocado a diseñar su propio sistema de clasificación, a definir las reglas de agrupación de los individuos. Su ideología fixista interpreta la especie como una unidad de origen; etología y morfología están reguladas por leyes constantes desde la Creación. En consecuencia, su taxonomía es una relación de semejanzas alejada de cualquier vínculo filogenético por la independencia de las especies en su génesis. Con Buffon el individuo representa la naturaleza. La sistemática se define como ficción no por la irrealidad del planteamineto sino ante las limitaciones del intelecto humano, incapaz de conocer las producciones naturales en toda su extensión. Para el filósofo «le seul moyen de faire une méthode instructive \& naturelle, c'est de mettre ensemble les choses qui se ressemblent, \& de séparer

1 AZARA, F. (1802), Apuntamientos para la historia natural de los quadrúpedos del Paraguay y río de la Plata, Madrid, Vda de Ibarra, t.I, p.V.

12 Ibidem, p.VII. 
celles qui diffèrent les unes des autres» ${ }^{13}$. El método natural conlleva el conocimiento del todo y de todos para determinar las relaciones de proximidad entre los miembros del elenco natural que, en su caso, responde al nombre de cadena de los seres, entendida como una secuencia descendente de perfección, presidida y gobernada por el hombre, abierta a la filogenia ${ }^{14}$. La idea resulta quimérica por el desconocimiento imperante sobre el reino animal, ante la imposibilidad de configurar los infinitos peldaños de la escala.

Azara y Buffon ofrecen distintas interpretaciones del orden natural: afirmación y negación de la sistemática, en función de un mismo parámetro: la ignorancia. Para aquél, clasificar conduce hacia el saber; para éste, el desconocimiento impide la clasificación. Sin embargo, en uno y otro la taxonomía, incluso utópica, recorre caminos paralelos, resulta de la comparación de todas las partes que componen el individuo, está reglada por el porcentaje de semejanzas y diferencias resultante. La definición del método natural como el resultado de «les raports de toutes leurs parties 爻 qualités, sans excepter une seule», expresada por Adanson en su Familles des plantes ${ }^{15}$, procede de Buffon ${ }^{16}$ y se vislumbra en Azara ${ }^{17}$.

Al ideal sistemático que caracteriza al concepto de especie como soporte teórico une Buffon la prueba empírica de la fecundidad; atributo expresado por la viabilidad reproductora de la descendencia. «Buffon y la mayoría de los naturalistas creían que para probar la identidad de especie basta que de la unión de un macho y una hembra nazcan individuos fecundos. Es verdad que yo no he adoptado esta opinión en mis noticias para servir a la historia natural de los mamíferos de Paraguay» ${ }^{18}$, expone Azara. La negativa contempla distintos aspectos. Junto a las pruebas sobre la capacidad reproductiva de los híbridos aportadas por los animales domésticos, la arbitrariedad empleada por Buffon en su Historia Natural, utilizando interesadamente el criterio de interfecundidad ${ }^{19}$, justifican una duda razonable. El rechazo es consecuencia de la realidad y de la tergiversación ideológica, no es tanto la refutación de una hipótesis como la negazión de un planteamiento especulativo. En su órbita fixista, Azara no necesita propiedades colectivas; conocer con precisión al individuo es requisito suficiente y necesario para definir la especie.

13 Buffon (1749), Histoire Naturelle, générale et particuliére, avec la description du Gabinet du Roy, Imp. Royale, Paris, t.I, p.21.

14 CF. Galera, A. (1994), «Reflexiones sobre el modelo sistemático, el concepto de especie v el mecanismo de la reproducción, en el siglo XVIII»; en Nouveau Monde et Renouveau de l'Histoire Naturelle, III; Presses de la Sorbonne Nouvelle, pp.97-130.

15 AdAnson, M. (1763), Familles des plantes, Paris, t.I, p.CLV.

I6 Buffon (1749), t.I, p.21.

17 AZARA, F. (1802), t.I, p.II.

18 AZARA, F. (1969), Viajes por la América meridional, Espasa Calpe, Madrid, p.250.

19) Cf. Azara, F. (1802-5), t.III, p.1 y ss; y Azara, F. (1802), t.I. p.85 y ss. 


\section{HISTORIA DE AMÉRICA}

La conquista científica de América llevó la controversia a la historia natural. Nuevos hombres, nuevos animales, diferentes ecosistemas. La cuestión a resolver es el porqué de tal diversidad geográfica. Azara, leyendo a Buffon, descubre el otro continente sometido a la ley del clima. América es para el sabio francés una tierra de promisión, un ecosistema joven, ajeno aún a la intervención del hombre, donde la Naturaleza no ha tenido tiempo de ejecutar todos sus planes. Un lugar que da cobijo a un número pequeño de especies, donde los cuadrúpedos son pequeños, grandes los reptiles e insectos, y los hombres, etológicamente, fríos, por la insalubridad y la falta de calor de la atmósfera ${ }^{20}$. La orografía al otro lado del Atlántico propicia un clima desfavorable a la vida: «La Nature vivante y est donc beaucoup moins agissante, beaucoup moins variée, et nous pouvons même dire beaucoup moins forte» ${ }^{21}$.

La diversidad zoológica está representada por dos grupos faunísticos: animales exclusivos del territorio americano y aquéllos comunes a sendos continentes. La división implica la génesis in situ de una fauna autóctona y la existencia de pretéritos episodios migratorios entre ambas márgenes del océano, a través de un imaginario nexo terrestre situado en el hemisferio norte; sendero para la migración de los moradores de las regiones frías, favorecidos por las condiciones climáticas del Nuevo Mundo. Un grupo zoológico cuya presencia en el continente americano hace plausible el extinto paso intercontinental, y refuerza su teoría climática. La interpretación cosmogónica tiene un mensaje implícito: la idea de cambio. Un transformismo sustentado en la influencia del medio ambiente: el clima y la litosfera, con el concurso del tiempo, son responsable de la especiación de individuos con un origen común ${ }^{22}$.

A esta cualidad degenerativa se opone Azara, rechazando el clima como factor inductor del cambio. «Parece que Buffon es de parecer, que los climas todo lo alteran, y que el de América disminuye la magnitud a las bestias, siendo incapaz de producir del tamaño que en otras partes. Pero a mi ver en todo se equivoca» ${ }^{23}$. En su lugar elabora un discurso sobre el origen polifilético de las especies, negando cualquier éxodo faunístico entre uno y otro continente, postulando la condición aborigen de unos habitantes comparables en tamaño, fuerza, agilidad, destreza, vigor y belleza, con Europa.

El interrogante geográfico ha sido resuelto desde opciones opuestas. La propuesta fixista argumenta un modelo de creación múltiple que distribuye una misma especie

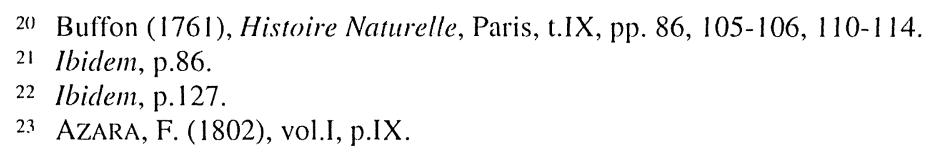


por diferentes parajes de la Tierra. La ideología transformista explica el fenómeno de la especiación por la influencia que el medio ejerce en los seres vivos.

\section{EL HOMBRE AMERICANO}

El libreto de esta representación se titula "Historia del Nuevo Mundo". Y en la escenificación el término historia es un valor clásico, una relación del presente y no un recuerdo del ayer. Narración donde el salvaje americano es un componente más de una naturaleza que «Dans cet état d'abandon tout languit, tout se corrompt, tout s'étouffe» ${ }^{24}$, opina Buffon. Aquí no se manifiesta su liderazgo zoológico, no se hace patente su perfección. El indio es un ser distribuido en grupos pequeños, errante, sin tierra que dominar ni imperio que defender, incapaz de someter a los animales y ni a los elementos, que no escapa al empequeñecimiento generalizado de la naturaleza en el nuevo mundo: el salvaje, escribe Buffon, «est foible et petit par les organes de la generation; il n'a ni poil, ni barbe, ni nulle ardeur pour sa femelle; quoique plus léger que l'européen parce qu'il a plus d'habitude à courir, il est cependant beaucoup moins fort de corps; il est aussi bien moins sensible, et cependant plus craintif et plus lâche; il n'a nulle vivacité, nulle activité dans l'ame; celle du corps est moins un exercice, un mouvement volontaire qu'une nécessité d'action causée par le besoin; ôtez-lui la faim et la soif, vous détruirez en même temps le principe actif de tous ses mouvemens; il demeura stupidement en repos sur ses jambes ou couché pendant des jours entiers» ${ }^{25}$. Una declaración de inferioridad que Azara rechaza argumentando la superioridad anatómica de unos nativos ${ }^{26}$ cuya indolente existencia, al amparo de una naturaleza que los alberga y sustenta, no es un signo de debilidad, sino que expresa la armonía que gobierna las relaciones de los organismos fuera de la sociedad humana.

Inferioridad y armonía son, pues, los adjetivos que acompañan al sustantivo indio al valorar su relación con la naturaleza. Sobre él recaen también otras cuestiones antropológicas a debate: ¿Cuál es su origen? ¿Cuál el color primigenio del hombre? La divergencia de las respuestas sintoniza con la pluralidad ideológica. Para Buffon, defensor del origen monofilético de las especies, también el hombre americano es una consecuencia del clima: «Dès que l'homme a commencé à changer de ciel, et qu'il s'est répandu de climats en climats, sa nature a subi des altérations» ${ }^{27}$. Las razas de América responden a esta experiencia climática capaz de trasformar su morfología

\footnotetext{
24 Ibidem, p.110.

2.5 Ibidem, p. 104.

26 AZARA, F. (1969), p.171.

27 Buffon (1984), «De la dégéneration des animaux», en Histoire Naturelle, édition de J. Varloot, Gallimard, Paris, p. 223.
} 
y etología, cuyos antecesores son emigrantes del norte de Europa atraídos por una climatología más benigna ${ }^{28}$. Azara, en sintonía con Voltaire ${ }^{29}$, ante la imposibilidad migratoria, proclama el origen poligenésico de la especie.

Más provocativa resulta la apuesta antropológica frente al problema de la pigmentación. Si el discurso buffoniano distribuye el color del hombre según regiones más o menos cálidas, el negro sería una consecuencia del calor, Azara acude a la fisiología, y explica las diferencias pigmentarias por una alteración orgánica materna. ¿Cuál fue, pues, el color primitivo del Homo sapiens? La respuesta tiene una dimensión potestativa derivada de la emulación del orden natural que los ilustrados quieren para su sociedad. Si Buffon manifiesta una actitud conservadora diagnosticando que el blanco es «el color primitivo de la naturaleza, que el clima, la alimentación y las constumbres alteran y cambian» ${ }^{30}$, un Azara sedicioso niega la hipótesis climática y contraviene la supremacía de la raza blanca en favor del color negro, que representa al hombre en la Creación y, consecuentemente, simboliza la perfección ${ }^{31}$.

\section{LA ACADEMIA DE CIENCIAS DE PARÍS}

En 1801 Lacepède, Cuvier y Richard, informaban a la Academia francesa de la publicación de L'essai sur les quadrupèdes du Paraguay. La memoria aprobada se complace en el mérito del naturalista al estudiar la fauna de una región poco conocida. Resalta su contribución a la zoología, corrigiendo errores y dando a conocer nuevas especies. «On y trouvera aussi», anuncia el informe, «très souvent une discussion, faite avec beaucoup de sagacité, des opinions relatives à l'espèce décrite, et publiées par diverse naturalistes, notemment par Buffon. Cette critique annonce toujours dans Don Félix d'Azara le talent de bien observer et un grand amour de l'exactitude» ${ }^{32}$. Polémica que, desde una óptica general y relegando a un segundo plano diferencias ideológicas, fixismo y transformismo, podemos considerar como un enfrentamiento entre la razón y la observación. No se trata de ejemplarizar la fabula baconiana de arañas y hormigas. Ambos contendientes, siguiendo la terminología de Francis Bacon, son abejas más o menos preocupadas por la filosofía y la experimentación. La cuestión es discernir qué materia debe prevalecer en el estudio de las

\footnotetext{
28 Buffon (1986), Del hombre. Escritos antropológicos, Fondo de Cultura, México, p.238 y ss.

29 VOLTAIRE, «Population», en Questions sur l'Enciclopédie, ed. Garnier, IV, pp.254-55. De este argumeto también habla Voltaire en sus Essai sur les Moeurs et l'esprit des nations.

31) Buffon (1986), p.233.

31 AZARA, F. (1802), t.II, p.234.

32 Rapport de Lacepède, Cuvier, Richard, a la Académie des Sciences, 26, Brumaire, 1801. Procèsverbaux des séances de l'Académie, Imp. de L'Observatoire d'Abbadia, Hendaye, 1912, t.II, p.270.
} 
ciencias naturales. Los ojos de la mente con los que Buffon sustituye al experimento y proclama la capacidad intelectual del hombre para conocer a través de la razón, se oponen al celo empírico, a la necesidad de ver para creer, presente en un Félix de Azara displicente con esa dimensión literaria que, como afirma Jacques Roger, permite al lector descubrir en Buffon «un écrivain là où il ne pensait rencontrer qu'un savant» ${ }^{33}$. Asistimos al final de un modelo científico, al fin de la historia natural ${ }^{34}$. Los sabios románticos y positivistas del siglo XIX estudiarán la vida terrestre guiados por el reduccionismo de los procesos vitales y el integrismo filogenético, alejándose del paradigma de la Naturaleza.

La crítica azariana es un ejemplo de la capacidad individual de los ilustrados españoles para renunciar al papel de comparsas y subir al estrado de la comunidad científica europea. Desafortunadamente, nuestra historiografía, a la búsqueda de mayor fortuna histórica, ha querido ver en su persona un precedente del evolucionismo darwinista ${ }^{35}$, circunstancia que no corresponde con el espíritu fixista de su doctrina biológica ${ }^{36}$, olvidando sus méritos como estudioso de la fauna americana y experiencias intelectuales como la presente. Acontecer merecedor de nuestra atención tanto en el ámbito nacional como para el ideal universal promovido por los sabios de las Luces.

33 Roger, J. (1993), Les sciences de la vie dans la pensée francaise au XVIIle siècle, Albin Michel, Paris, p.527.

34 W. LEPENIES, W. (1976), Das Ende der Naturgeschichte, C. Hanser Verlag, Müchen-Wien. Citamos por la traducción italiana, La fine della storia naturale, Il Moulino, Bologna, 1991. También, Barsanti, G. (1979), Dalla storia naturale alla storia della natura, Feltrineli, Milano.

35 Cf. Alfageme, C. \& Almazán, M. (1987), Félix de Azara ingeniero militar y naturalista, CSIC, Huesca. Álvarez, E. (1943), «FÉLIX DE AZARA, precursor de Darwin», Revista de Occidente, vol. 43, pp. 149-166; «Ensayo acerca de las ideas biológicas de Azara», Boletín de la Sociedad Española de Historia Natural, reseñas científicas, t.VIII, 1933 pp. 19-49; Félix de Azara, Biblioteca de Cultura Española, Ed. Aguilar, Madrid, 1935; «Comentarios y anotaciones acerca de la obra de D. FÉLIX DE AZARA», Miscelánea Americanista, vol.III, Inst. Gonzalo Fernández de Oviedo, 1952, pp.9-62. Baulny, O., «FÉLIX DE AZARA. Un aragonais precurseur de Darwin», Pyrenées, nº 68-9, 70-1, 72, 73.

36 Consúltese la introducción de F. AzARA, Descripción general del Paraguay (edición, introducción y notas de A.Galera), Alianza Editorial, Madrid, 1990, pp.7-38. 